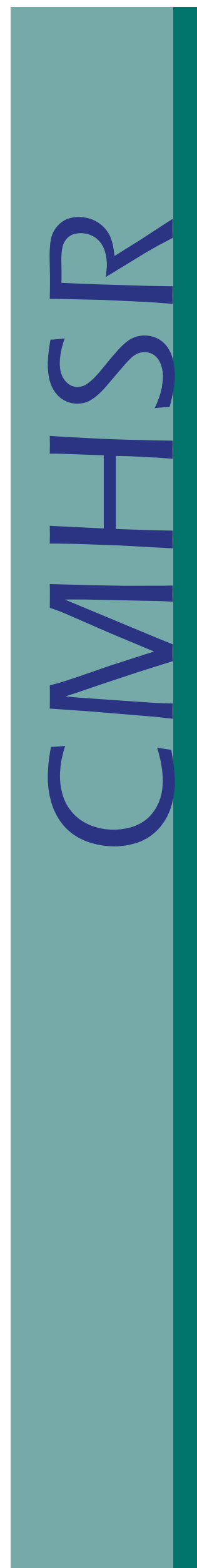

December 2004

Vol 1, Issue 10

\title{
Issue
}

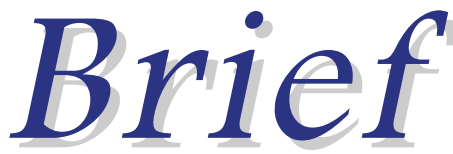

\section{Developing Mental Health Screening in Juvenile Justice}

$\mathrm{R}$ ecent events have brought the mental health needs of youths involved in the juvenile justice system to the forefront of public health concerns. New research has reported that around $70 \%$ of youths in detention and correctional facilities meet criteria for at least one DSM diagnosis. ${ }^{1,2}$ News reports from various states have highlighted the poor treatment of juveniles' mental health needs. Finally, a congressional report discovered that, during FY 2001, more than 9,000 youths were placed in U.S. juvenile justice facilities because inpatient mental health services were not available. ${ }^{3}$ The majority of these youths had not even been charged with a crime.

Increasing demands to respond to mental health needs of youths in custody has been felt by virtually every state over the past 10 years, when juvenile detention facilities began to report an influx of youths with mental disorders. A compelling explanation for this trend is the legislation of more punitive laws for youthful offenders during the 1990s that decreased judicial discretion for diverting youths with mental disorders to other services, and a concomitant nationwide deterioration of children's mental health services that resulted in the use of detention facilities to deal with the unmet needs.

\section{The Drive Toward Mental Health Screening}

Juvenile justice facilities have a legal and moral obligation to care for the mental health needs of minors in their custody given incarcerated youth are unable to seek treatment elsewhere. ${ }^{4}$ The juvenile justice system's obligation to protect public safety also requires attention to youths' mental disorders to the extent that they are associated with aggression. This is not to say that the juvenile justice system should be expected to provide treatment to the $70 \%$ of their population estimated to have a diagnosis. Not all youths with diagnoses have symptoms that are severe enough to require psychiatric care. Moreover, in many ways juvenile justice programs are not the best places to provide effective psychiatric treatment. But the system should develop ways to obtain treatment-for example, from mental health agencies-when it is needed.

The first step toward managing the mental health needs of juveniles is to be able to identify them. Mental health screening is crucial for identifying mental conditions in need of immediate response, such as suicide risk, while also targeting youths requiring further assessment to formulate aggression management and treatment strategies. Federal and state governmental agencies are encouraging the implementation of routine mental health screening in public systems serving youth. In July 2003, the President's New Freedom Commission on Mental Health report called for "early mental health screening, assessment, and referral to services" (p. 17) to become common practice. Bringing this goal to the juvenile justice system, both the Substance Abuse and Mental Health Services Agency and the Office of Juvenile Justice and Delinquency Prevention have initiated block grant programs funding states to implement routine screening procedures throughout their juvenile facilities.

\section{Considerations in the Implementation of a} Screening and Assessment Process

CMHSR faculty recently edited a book, Mental Health Screening and Assessment for Juvenile Justice, to provide a resource for juvenile justice officials seeking to adopt standard screening and assessment procedures. ${ }^{5}$ The 
book will be available in April 2005. It outlines considerations for implementation and contains chapters that review the purpose and psychometric properties of many psychological instruments available for screening and assessment in juvenile justice.

To summarize the main points of this book, effective screening and assessment procedures require attention to the quality of the instruments and the degree to which they can function within the context of juvenile justice settings, generally including initial intake or entry into juvenile detention or correctional facilities. How screening occurs, what facilitates its use, and what drives its purposes requires a consideration of the system's objectives, practical demands of juvenile facilities, and capacities for response.

Objectives. Development of procedures must begin with a clear view of the motivations for screening. Most screening tools will identify youth in need of immediate attention but will differ in their ability to meet other objectives. Three objectives are particularly common.

- Fulfilling Regulatory Requirements imposed by the law, state, county, or professional standards. Although these directives typically do not specify the mental health needs for screening, consensus dictates that tools need to indicate affective and anxiety symptoms, and the short-range likelihood for aggression, self-harm, and serious substance abuse at the minimum;

- Improving Staff Decisions for managing youth. Appropriate tools will be highly structured, have clear training methods, and will produce scores that can be translated into management decisions; and

- Managing Resources to meet broader program objectives by providing data, such as prevalence rates, to project financial and other needs.

Costs and Feasibility. A screening process must fit the practical demands of the facility. Instruments favored for screening are those that require minimal resources to implement and administer, yet have known reliability and validity. Practical considerations for selecting a tool include the availability and need for collateral information, expertise required of staff for administration, efficiency of administration, and the cost of the test materials.

Capacity for Response. Implementation of screening also requires administrators to determine when and how they are going to respond to youths who score at significant levels on screening instruments. Often this requires development of relations with mental health services in the community, examining the research on what services are and are not effective, and assuring that decision rules for responding are clearly manualized for staff.

\section{Policy Recommendations}

In light of the developments in practice for handling mental health concerns in juvenile justice systems, we recommend that juvenile justice systems:

- Develop mental health screening of emergency and other serious mental health needs during intake to pretrial and correctional facilities;

- Select a mental health screening tool valid for juvenile justice settings and commensurate with custodial obligations;

- Design a structured and feasible policy for making decisions about response, referral and further assessment when youths manifest high needs in screening;

- Develop interagency arrangements that will allow juvenile justice facilities to refer youth with emergent conditions to appropriate services; and

- Pursue federal funding for these efforts to strengthen the ability to respond to the needs of youth.

\section{References}

1. Teplin, L. A., Abram, K. M., McClelland, G. M., Dulcan, M. K., \& Mericle, A. A. (2002). Psychiatric disorders in youth in juvenile detention. Archives of General Psychiatry, 59, 1133-1143.

2. Wasserman, G. A., McReynolds, L. S., Lucas, C. P., Fisher, P., \& Santos, L. (2002). The Voice DISC-IV with incarcerated male youths: Prevalence of disorder. Journal of the American Academy of Child and Adolescent Psychiatry, 41, 314-321.

3. General Accounting Office (2003). Child welfare and juvenile justice: Federal agencies could play a stronger role in helping states reduce the number of children placed solely to obtain mental health services (GAO-03-397). Washington, DC: U.S. General Accounting Office.

4. Grisso, T. (2004). Double Jeopardy: Adolescent Offenders with Mental Disorders. Chicago: University of Chicago Press.

5. Grisso, T., Vincent, G. M., \& Seagrave, D. [Eds.] (in press) Mental Health Screening and Assessment for Juvenile Justice. Guilford Press.

Visit us on-line at www.umassmed.edu/cmhsr 